Sharif University of Technology
Scientia Iranica
SCIENTIA $\quad \begin{gathered}\text { Transactions D: Computer Science Es Engineering and Electrical Engineering } \\ \text { I RAN I C A }\end{gathered}$

\title{
A novel transverse flux permanent magnet generator for small-scale direct drive wind turbine application: Design and analysis
}

\author{
A. Mohammadi Ajamloo ${ }^{a}$, K. Abbaszadeh ${ }^{a}$, and R. Nasiri-Zarandi ${ }^{b}, *$ \\ a. Department of Electrical Engineering, K.N. Toosi University of Technology, Tehran, Iran. \\ b. Electrical Machine Group, Niroo Research Institute (NRI), Tehran, Iran. \\ Received 12 March 2018; received in revised form 21 May 2019; accepted 20 July 2019
}

\author{
KEYWORDS \\ Cogging torque; \\ Direct drive wind \\ turbine; \\ Ferrite permanent \\ magnet; \\ Magnetic equivalent \\ circuit; \\ Permanent magnet \\ demagnetization; \\ Transverse flux \\ permanent magnet \\ machine.
}

\begin{abstract}
This study proposes a special topology of transvers flux permanent magnet generator, which benefits from low Permanent Magnet (PM) costs due to use of cheap Ferrite PMs. In this structure, only one PM per phase is used to ensure easy manufacturing. Despite the above-mentioned advantages of the topology, it is subject to some disadvantages such as unbalanced voltage, high demagnetization risk of the PM, and high cogging torque. Aiming to solve these problems and maintaining the advantages of the topology, a new structure is proposed. The stator of this structure contains two series connected coils that eliminate all the even-order harmonics and balance the voltage waveform. This trick reduces the armature reaction as well as demagnetization of the PMs significantly. Moreover, the rotor teeth of the proposed structure are skewed, causing a significant reduction in cogging torque. The output results of the proposed structure are compared with those of the original one in terms of harmonic components, cogging torque profile, and PM demagnetisation.
\end{abstract}

(C) 2021 Sharif University of Technology. All rights reserved.

\section{Introduction}

Transverse Flux Permanent Magnet Machines (TF$\mathrm{PMs}$ ) are special types of electrical machines with high torque density and large number of poles [1-3]. These specifications make TFPMs suitable for direct drive wind turbines that have many advantages over geared ones like lower maintenance cost and higher efficiency $[4,5]$.

Generally, in TFPMs, the number of rotor poles is half of, equal to, or twice the stator teeth. Con-

\footnotetext{
*. Corresponding author.

E-mail address: Rnasirizarandi@nri.ac.ir ( $R$. Nasiri-Zarandi)
}

doi: $10.24200 /$ sci. 2019.53145 .3078 sequently, the large value of the cogging torque is an intrinsic characteristic of the TFPMs that must be reduced to make them suitable for direct drive wind turbine applications [6,7]. The large value of cogging torque prevents the turbine from starting up and causes massive noise and vibrations in the structure [8-11]. Cogging torque hastens blade fatigue failure which reduces the turbine life time. Some studies have been conducted to reduce the cogging torque of the transverse flux Permanent Magnet (PM) machines. In [12], the effects of skewing stator U-shaped cores and the unequal distribution of the U-cores were investigated. However, skewing a large number of individual U-shaped cores makes the construction of TFPMs more complicated and this does not seem to be a cost-effective solution. The effect of shifting the stator teeth along with unequal stator tooth width was 
studied in [13]. In this method, the cogging torque reduction is successfully achieved, but a considerable decrease in the machine average torque is achieved as its side effect. The PM dimensions were optimized to minimize the cogging torque of the TFPM in [14]. In this method, a large number of PMs with different dimensions are required that complicate the machine assembly process and require high manufacturing effort. Unequal pole pitch of the rotor was investigated in [15] and a noticeable reduction in cogging torque along with improvement in voltage harmonic components was achieved at the cost of a considerable reduction in machine average torque. The application of different Halbach-Array structures was also studied in [16]. Use of Halbach-array of PMs requires magnetizing the PMs in different directions which could be troublesome and expensive in the mass production of TFPMs.

There are some difficulties associated with the application of PMs in TFPMs. In most of TFPM topologies, especially conventional topologies in $[17,18]$, the PM cost is considerable because of the partial application of PMs to magnetic circuit. Many papers have attempted to reduce the PM cost by substituting the cheap Ferrite for expensive rare earth PMs [4,1923].

Significant manufacturing efforts for placing a large number of surface mounted PMs, complicated manufacturing procedure, and low level of reliability are other deficiencies of TFPMs $[17,19,24]$. Increasing the torque density was perused by proposing a new stator structure in [25]. A novel TFPM topology was introduced in [19] which had some advantages over typical TFPMs. The TFPM uses Ferrite PM instead of expensive NdFeB PM. The TFPM uses only one PM per phase that facilitates the manufacturing process in comparison with typical TFPMs. In this topology, the PM eddy current loss is almost zero due to high electrical resistance of the ferrite PM. In spite of these advantages, the TFPM has a unipolar flux linkage that obtains significant value of even order harmonics, which results in an unbalanced voltage. Besides, due to the application of weak Ferrite PM, the armature reaction easily demagnetizes the PM. The torque ripple of the TFPM is measured by a high value which is another drawback of the topology.

Wind turbines are mainly designed as Horizontal Axis Wind Turbines (HAWTs) or Vertical Axis Wind Turbines (VAWTs). HAWTs outperform VAWTs in terms of efficiency. Moreover, they can be installed at higher heights where high speed winds are available. However, the VAWTs have some advantages over HAWTs like lower maintenance cost and lower acoustic noise [26]. Generally, for mechanical considerations, the nominal speed of the turbine decreases as the nominal power increases, as can be seen in Figure 1. This figure represents the nominal working points of

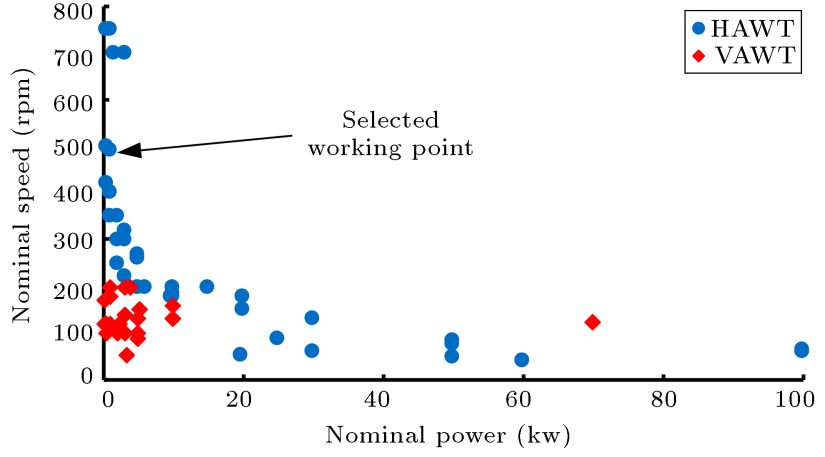

Figure 1. Nominal working point of small-scale direct drive wind turbines available in the market.

various small-scale direct drive wind turbines (available in market). The TFPM of this paper is designed for the $1.5 \mathrm{~kW}$ direct-driven HAWT with a nominal speed of $500 \mathrm{rpm}$.

This paper aims to overcome the deficiencies of this topology [19], i.e., the presence of even order harmonic voltage components, high risk of PM demagnetization, and high value of torque ripple, using a new stator structure. The proposed topology includes two coils that are cascaded together negatively. As a result, the flux linkage has a unipolar form where all even order harmonics will be cancelled. In addition, the demagnetization risk of the ferrite reduces significantly due to splitting the armature reaction between two coils. In order to minimize the torque ripple, skewing rotor teeth is proposed which is a feasible and cost-effective procedure. In the first section, two configurations of Single Permanent Magnet-Transverse Flux Machine (SPM-TFM) are introduced and the operation principles are discussed. Next, the output equations of both structures are extracted using the analytical approach. Then, by using the 3D finite element approach, the performance of both topologies is compared in terms of voltage harmonic components and demagnetization behavior of the PMs. At the end, to reduce the torque ripple and cogging torque of the SPM-TFM, a technique based on the rotor tooth skewing is applied.

\section{Operation principle of original and proposed structures}

Figure 2(a) shows the rotor configuration of the SPMTFMs. The rotor is composed of a ring-shaped ferrite PM and solid salient poles arranged on the upper and lower sides of the PM. The ring-shaped PM is magnetized uniformly in the axial direction. The stator structure of the basic topology [19], which is presented in Figure 2(b), consists of C- and I-shaped silicon-steel laminations surrounding a single coil of winding. By combining $\mathrm{C}$ - and I-shaped laminations, a special shape of the stator core is proposed (Figure 2(c)), hosting two 

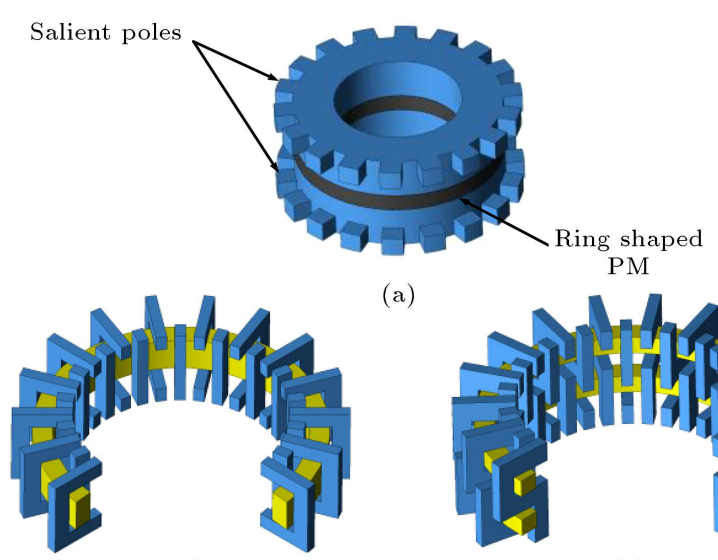

(b)

(a)

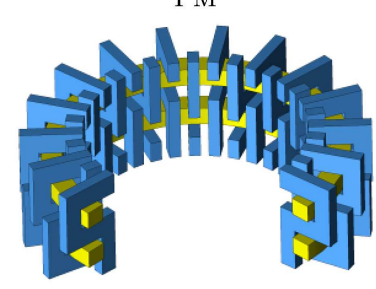

(c)

Figure 2. Configuration of the Single Permanent Magnet-Transverse Flux Machines (SPM-TFMs): (a) Rotor structure, (b) stator of the basic topology, and (c) stator of the proposed topology.

series of coils on the upper and lower sides, which are connected in series. The rotor configuration for both topologies is the same.

From the authors' perspectives, the inner rotor configuration is selected mainly based on the type of the PM used in the machine. It is evident that machine output power significantly decreases through the replacement of high power density NdFeB PMs by weak ferrite. The only way to avoid this occurrence is to increase the machine volume so that the larger amount of ferrite PMs could be accommodated. In the case of selecting the inner rotor configuration, the inner diameter of the rotor should be mainly reduced to increase the space for accommodating the ferrite PM. In doing so, the machine outer diameter does not increase and even better usage of machine volume is achieved. However, it is unavoidable that the machine weight will increase. Moreover, PM demagnetization is more likely because of lower magnetic field strength of the ferrite PM.

In order to clarify the operation concept of the structures, the flux linkage of the basic machine in two rotor positions is investigated. Figure 3(a) presents a cross-sectional view of the basic machine where the rotor teeth are located in front of the U-shaped parts and rotor slots are aligned with the I-shaped parts. Based on the flux path in Figure 3(a), the main portion of the flux lines passes from U-shaped parts into the rotor via teeth and leads to the maximum achievable value of the flux linkage. With one pole pitch rotation of the rotor (Figure $3(\mathrm{~b})$ ), the I-shaped core aligns with the rotor teeth where the U-shaped ones are located in front of the rotor slots and cause the minimum value of the flux linkage. To achieve a better understanding of the oscillation of the flux linkage in the structures, a sample machine is simulated using a software product by Finite Element Method (FEM) and the resulting waveform of the flux linkage is

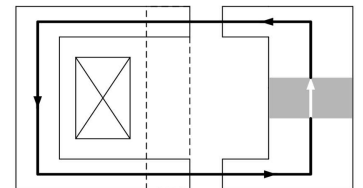

(a)

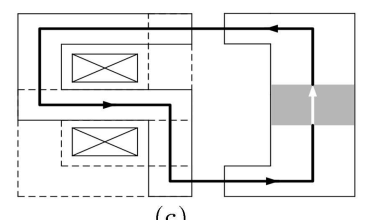

(c)

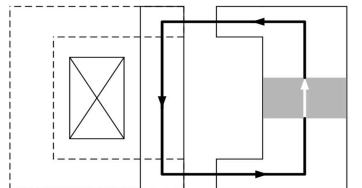

(b)

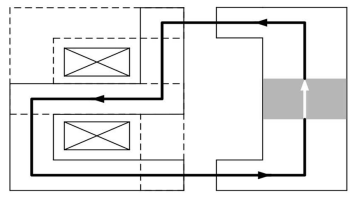

(d)
Figure 3. A cross-sectional view of the main flux path in the Single Permanent Magnet-Transverse Flux Machines (SPM-TFMs). Basic topology: (a) Initial position and (b) one pole pitch movement. Proposed topology: (c) initial position and (d) one pole pitch movement.

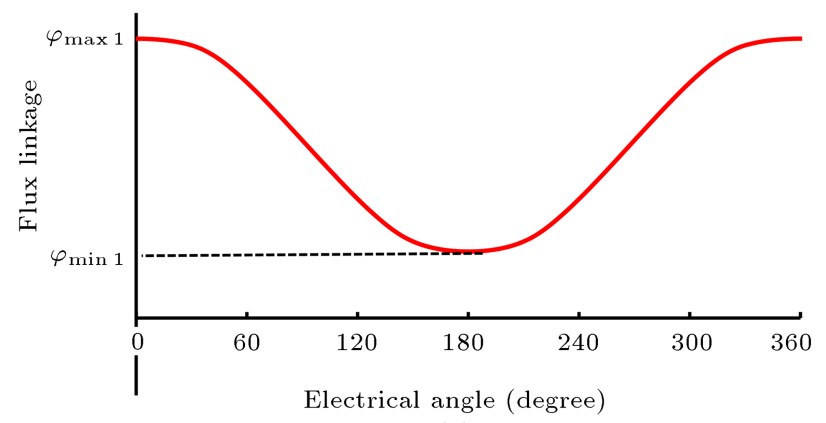

(a)

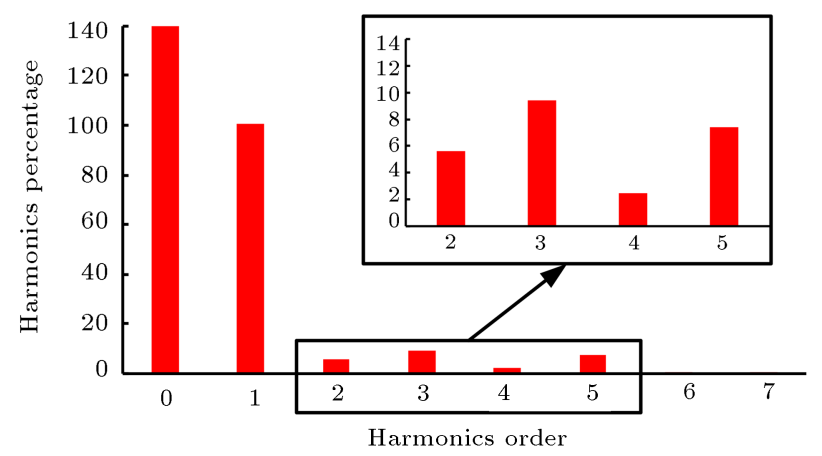

(b)

Figure 4. Flux linkage of the basic Single Permanent Magnet-Transverse Flux Machine (SPM-TFM): (a) Waveform and (b) harmonics component (percentage of main harmonic component).

extracted and presented in Figure 4(a). As can be seen, the coil flux linkage has a unipolar shape in which the flux value oscillates between maximum and minimum values $\left(\varphi_{\max } 1, \varphi_{\min 1}\right)$. The flux linkage waveform of this topology could be decomposed and written as a Fourier series as in Eq. (1):

$$
\phi_{a}=\phi_{0}+\sum_{n=1}^{\infty} \phi_{n} \cos \left(n \theta+\alpha_{n}\right), \quad n=1,2,3, \ldots
$$

The harmonics component of the flux linkage is extracted in Figure 4(b) as the percentage of the main 
component. The no-load flux linkage obtains $140 \%$ of DC component, $5.5 \%$ of second-order harmonics, and $2.5 \%$ of fourth-order harmonic component, which is the result of the unipolar nature of the flux linkage waveform. The existence of the even-order harmonics would cause unbalanced voltage waveform, high value of the Total Harmonic Distortion (THD), and increased machine loss.

To investigate the operation of the proposed topology, the same action is followed. In the initial position of the rotor, the flux lines are mostly linked to the upper coil. In such a position as depicted in Figure 3(c), the upper coil has the maximum flux linkage due to alignment with the rotor teeth, while the lower coil has a minimum flux linkage value because of its alignment with the rotor slot. After one pole pitch rotation of the rotor (Figure 3(d)), the flux mostly links the lower coil because of alignment with the rotor teeth where the upper coil aligns with the slots and have a minimum flux linkage value.

The flux linkage waveform of the upper and lower coils of the proposed topology is presented in Figure 5(a). As can be seen, the flux linkage of both coils has unipolar shapes. Flux linkage of the upper and lower coils could be written as in Eqs. (2) and (3), respectively.

$$
\begin{aligned}
& \phi_{\text {upper }}^{\prime}=\phi_{0}^{\prime}+\sum_{n=1}^{\infty} \phi_{n}^{\prime} \cos \left(n \theta+\alpha_{n}\right), \quad n=1,2,3, \ldots, \\
& \phi_{\text {lower }}^{\prime}=\phi_{0}^{\prime}+\sum_{n=1}^{\infty} \phi_{n}^{\prime} \cos \left(n \theta+n \pi+\alpha_{n}\right), \\
& n=1,2,3, \ldots
\end{aligned}
$$

By negatively cascading the coils, a bipolar flux linkage is found. The total flux linkage is obtained as follows:

$$
\begin{aligned}
& \phi_{b}=\phi_{\text {upper }}^{\prime}-\phi_{\text {lower }}^{\prime}=2 \sum_{n=1}^{\infty} \phi_{n}^{\prime} \cos \left(n \theta+\alpha_{n}\right), \\
& n=1,3,5, \ldots .
\end{aligned}
$$

Eq. (4) states that not only has the flux linkage a bipolar shape but also all the even-order harmonics are cancelled. The flux linkage harmonic components of the proposed structure are presented in Figure 5(b); in this respect, this statement is confirmed.

\section{Proposition of the design equations}

In this section, the torque and voltage equations for the SPM-TFMs are derived. In TFPMs, the armature coil has a circumferential arrangement; therefore, the Lorentz force equation could not be applied to the TFPMs directly [27-29]. In order to use the Lorentz

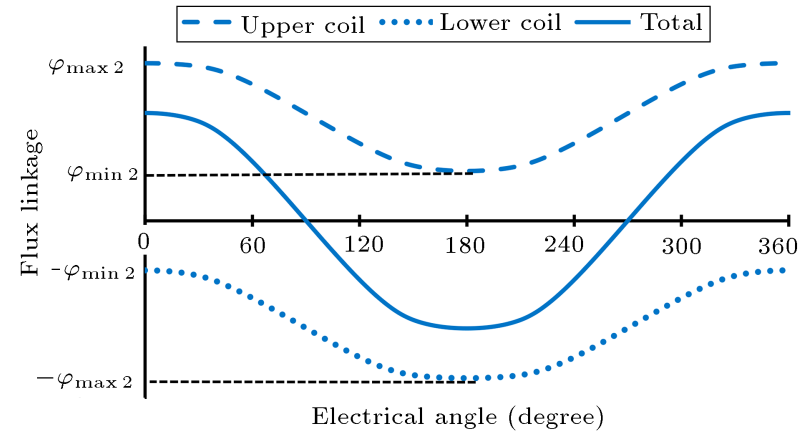

(a)

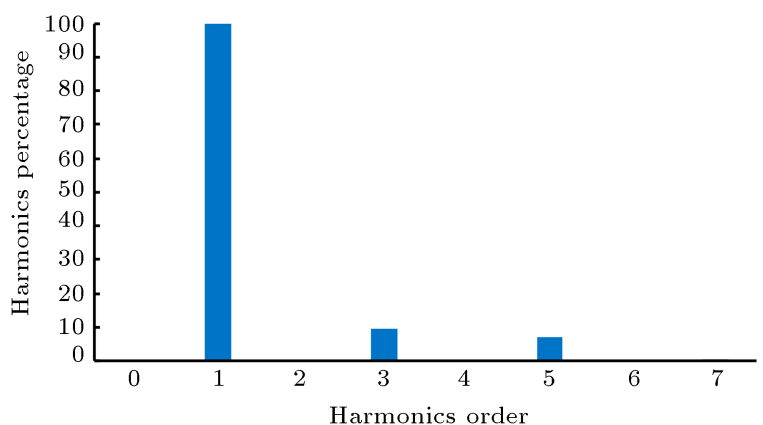

(b)

Figure 5. Flux linkage of the proposed Single Permanent Magnet-Transverse Flux Machine (SPM-TFM): (a)

Waveform and (b) harmonics component (percentage of main harmonic component).

force equation in SPM-TFMs, the ring-shaped ferrite $\mathrm{PM}$ is modeled by multiple surface mounted PMs on the rotor teeth. At first, the equivalent thickness and remanent flux density of these PMs as the surface mounted ones are calculated as in Eqs. (5) and (6), respectively.

$$
\begin{gathered}
t_{m}=\frac{P L_{m} L_{r} \tau}{2 S_{m}}, \\
B_{r}{ }^{\prime}=\frac{2 S_{m} B_{r}}{P L_{r} \tau},
\end{gathered}
$$

where $P$ is the number of poles, $L_{r}$ is the rotor tooth length, $L_{m}$ is the length of the ring-shaped PM, $\tau$ is the one-pole pitch length, $B_{r}$ is the remanent flux density of the ring-shaped PM, and $S_{m}$ is the surface area of the PM ring, which is perpendicular to the PM flux lines. Then, each PM is modeled by a single-turn coil located on the surface of the rotor, as shown in Figure $6[27,30]$. These coils are supposed to carry the equivalent current of $I_{m}$ as in Eq. (7):

$$
I_{m}=\frac{B_{r} L_{m}}{2 \mu_{0} \mu_{r}},
$$

where $\mu_{r}$ is the relative permeability of the ring-shaped PM. By considering $B_{(x)}$ as the armature magnetic flux density which is crossing the equivalent conductors and $x$ as the position of the rotor in the reference frame of 


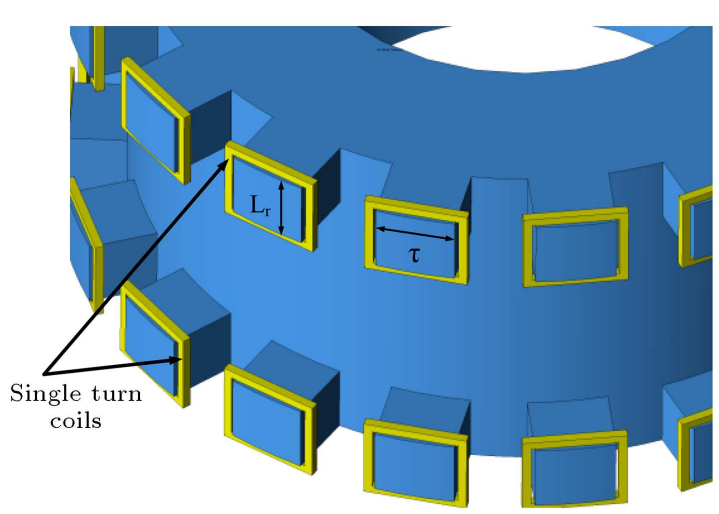

Figure 6. The equivalent single turn coils substituted for ring-shaped Permanent Magnet (PM).

Figure 7(a), the effective force on each conductor can be calculated based on the Lorentz force law as follows:

$$
F=B_{(x)} I_{m} L_{r}
$$

\subsection{Torque equation}

The armature magnetic flux density of the structure should be determined before calculating the electromagnetic torque of the generator. To this end, a theoretical estimated model is proposed to determine this parameter. Figure 7 represents a cross-sectional view of the machine in two rotor positions. In the initial position (Figure $7(\mathrm{a})$ ) where the U-shaped core aligns with the conductor $\mathrm{A}_{1}$, the conductor experiences maximum flux density. Hence, the maximum force is achievable regarding the Lorentz force of Eq. (8).

With one pole pitch rotation of the rotor (Figure $7(b))$, the conductor $A_{1}$ aligns with the I-shaped core. In this position, the effective force is almost zero because the flux line that crosses the conductor is almost zero. In terms of this modeling, the magnetic flux density crossing the conductor $\mathrm{A}_{1}$ in different rotor positions is estimated, as shown in Figure 8. It is assumed that the flux density crossing $A_{1}$ has a constant and maximum value under the U-shaped core. Similarly, the magnetic flux density crossing

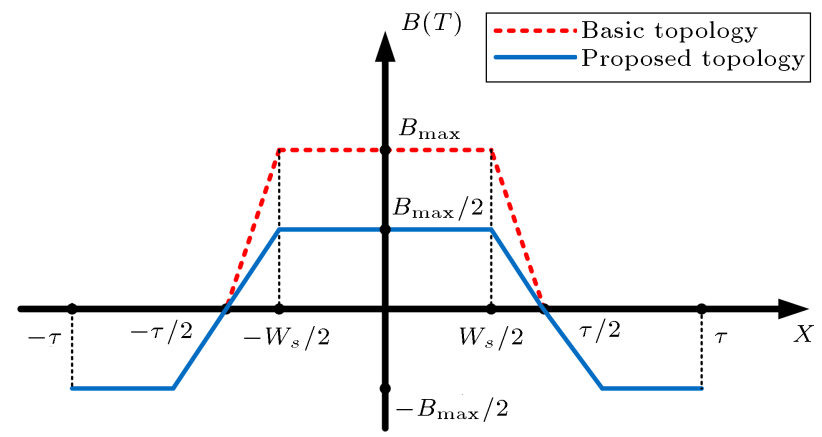

Figure 8. The estimated model of armature flux density crossing the conductor $\mathrm{A}_{1}$ in different rotor positions.

the conductor $A_{1}$ for the proposed topology could be modeled as the blue line in Figure 8 . The maximum flux density crossing the conductor can be calculated as in Eq. (9). Of note, both of topologies have an equal number of armature coil turns per phase $(N)$. Hence, in the proposed topology, the upper and lower coils have $N / 2$ turn per phase.

$$
B_{\max }=\frac{0.5 C_{f} \mu_{0} \mu_{r} N I_{s}}{t_{m}+\mu_{r} g}
$$

where $C_{f}$ and $I_{s}$ are the fringing factor and the armature current, respectively. The furrier series form of the magnetic flux density in Figure 8 can be extracted as in Eq. (10). Therefore, the electromagnetic torque of an $m$-phase SPM-TFM can be written as follows:

$$
\begin{aligned}
& B_{(x)}=\sum_{n=0}^{\infty} B_{n} \cos \left(\frac{n \pi x}{\tau}\right), \\
& T=0.5 m P D_{g} I_{m} L_{r}(B(x)-B(x+\tau)) .
\end{aligned}
$$

By considering the armature current as $I_{s}=$ $I_{a} \sin \left(\omega_{s} t-\varphi\right)$ and $\theta_{s}=\pi x / \tau=\omega_{s} t$, the average value of the electromagnetic torque is dependent on the main component of the $B_{(x)}$ as follows:

$$
T_{\text {ave }}=0.5 m P D_{g} I_{m} L_{r} B_{1} \cos (\varphi)
$$

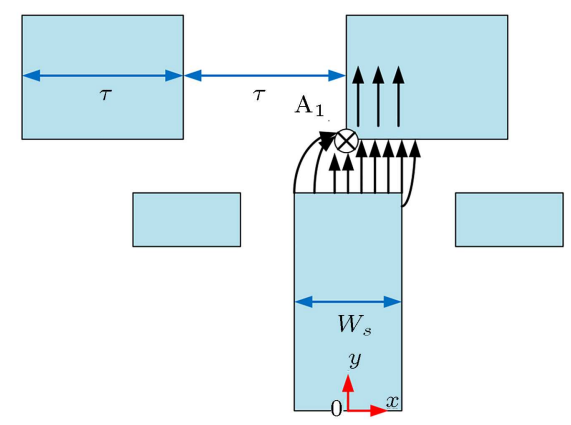

(a)
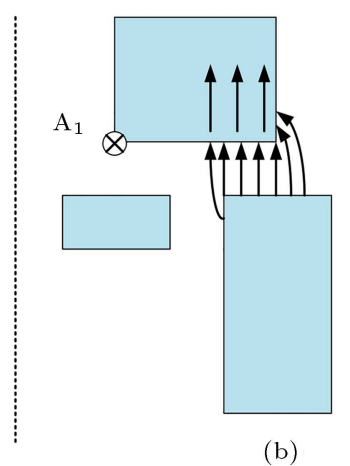

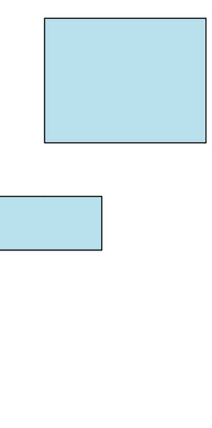

(b)

Figure 7. Magnetic field crossing the conductor $A_{1}$ in different rotor positions for basic topology: (a) Initial position and (b) one pole pitch movement. 
Table 1. Specification of the Single Permanent Magnet-Transverse Flux Machines (SPM-TFMs).

\begin{tabular}{lccc}
\hline Parameter & Symbol & Value & Unit \\
\hline Rated power & $P_{\text {out }}$ & 1.5 & $\mathrm{~kW}$ \\
Rated speed & $n_{m}$ & 500 & $\mathrm{rpm}$ \\
No. of phases & $m$ & 3 & - \\
No. of poles & $P$ & 36 & - \\
No. of rotor teeth & $N_{\text {rotor }}$ & 18 & - \\
Outer diameter of the rotor & $D_{\text {or }}$ & 195 & $\mathrm{~mm}$ \\
Inner diameter of the rotor & $D_{i r}$ & 80 & $\mathrm{~mm}$ \\
Length of one stator core & $L$ & 80 & $\mathrm{~mm}$ \\
Number of armature turns per phase & $N$ & 86 & - \\
PM coercive force & $H_{c}$ & -285 & $\mathrm{kA} / \mathrm{m}$ \\
PM remanent flux density & $B_{r}$ & 0.38 & $\mathrm{~T}$ \\
\hline
\end{tabular}

Here, $B_{1}$ is the main component of $B_{(x)}$. The value of $B_{1}$ for both topologies is as follows:

$$
\begin{cases}B_{1}=\frac{4 \tau B_{\max }}{\pi^{2}\left(\tau-W_{s}\right)} \cos \left(\frac{\pi W_{s}}{2 \tau}\right), & W_{s} \neq \tau \\ B_{1}=\frac{2 B_{\max }}{\pi}, & W_{s}=\tau\end{cases}
$$

By substituting Eq. (13) into Eq. (12), the average value of the electromagnetic torque for both topologies can be derived as follows (in the case of $W_{s}=\tau$ ):

$$
T_{\text {ave }}=\frac{m P D_{g} I_{m} L_{r} B_{\max }}{\pi} \cos (\varphi)
$$

\subsection{Back-EMF equation}

To derive the Back-EMF equation of the TFPMs, the effect of stator segments must be included in the voltage equation such as the proposed equation in $[1,27]$. In this paper, the PM flux density distribution in the air gap is modeled by the proposed graph given in Figure 9. The flux density distribution of PM in the air gap could be written in furrier series as in Eq. (15) where the first component of the magnetic flux density is calculated in Eq. (13) by replacing $B_{\max }$ with $B_{\max }-B_{\min }$.

$$
B_{(x)}=B_{m} \cos \left(\frac{\pi x}{\tau}\right) \text {. }
$$

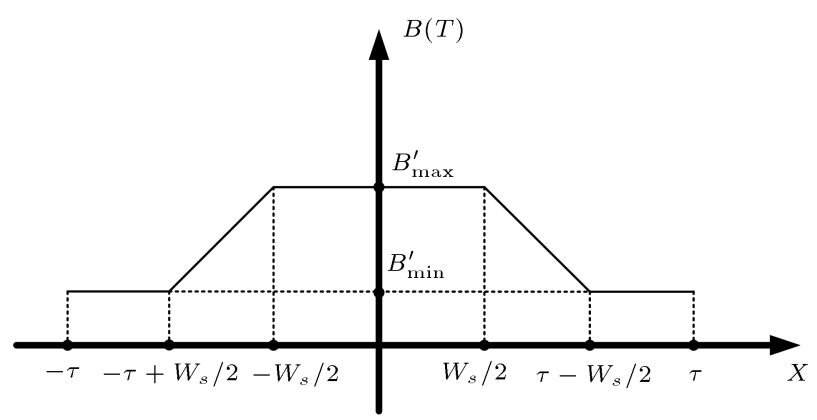

Figure 9. The model of Permanent Magnet (PM) flux density distribution in air gap.
The total flux linkage of the basic topology could be calculated as follows:

$$
\varphi=\frac{N P}{2} L_{r} \int_{-\tau / 2}^{\tau / 2} B_{(x)} d_{x}=\frac{N P L_{r} B_{m} \tau}{\pi} .
$$

By substituting Eqs. (15) and (16) into the general equation of induced voltage $(V=N d \varphi / d t)$, the RMS value of the Back-EMF can be calculated:

$$
V=\sqrt{2} f_{e} N P L_{r} B_{m} \tau
$$

where $f_{e}$ is the electrical frequency of armature. For the proposed topology with $N / 2$ turn per phase in each coil, the induced voltage per coil is half of the voltage in basic topology. Therefore, through the series connection of the coils, the induced voltage (main component) is equal for both topologies.

By using the proposed design equation, two different topologies of SPM-TFMs are designed for a smallscale direct drive wind turbine. As stated earlier, the selected power and speed for the case study turbine are considered as $1.5 \mathrm{~kW}$ and $500 \mathrm{rpm}$, respectively. The specifications of the designed SPM-TFMs are listed in Table 1.

In order to make a comparison between the topologies, all the specifications such as rotor dimensions, PM type, machine length, and machine outer diameter are supposed to be equal in the case of both topologies. To validate the design equations, the average torque and the main component of the BackEMF are derived using Finite Element Analysis (FEA) and analytical approaches. Figure 10 shows the torque waveform of the SPM-TFM resulting from FEA versus rotor position based on the dimensions given in Table 1. The average value of the FEA result and the torque value of Eq. (14) are also given in Figure 10. Upon comparing the average torque value resulting from FEA with the analytical equation of Eq. (14), an acceptable coincidence is produced that has only $6 \%$ divergence. 


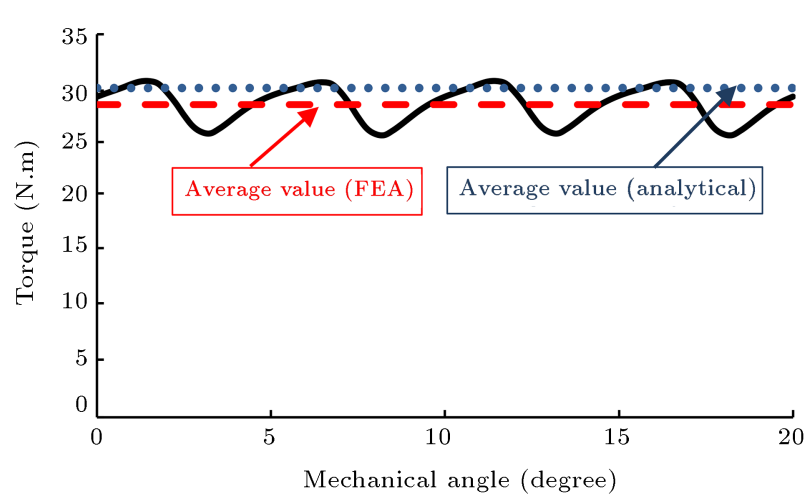

Figure 10. The output torque of the proposed Single Permanent Magnet-Transverse Flux Machine (SPM-TFM) calculated by Finite Element Analysis (FEA) and the analytical model.

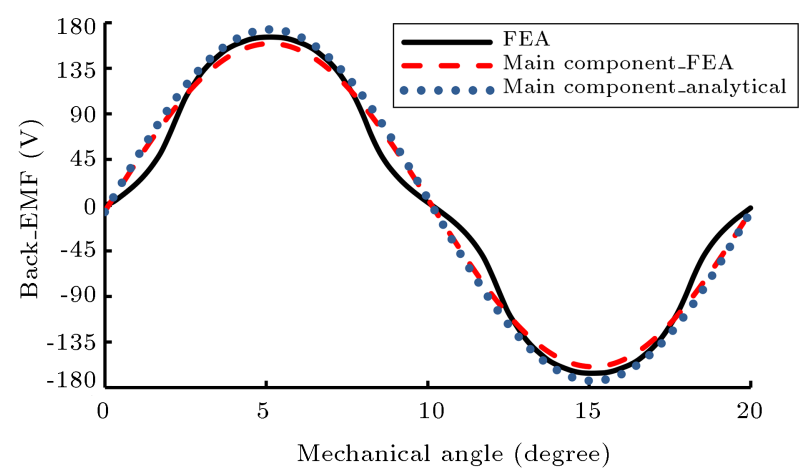

Figure 11. The Back-EMF of the proposed Single Permanent Magnet-Transverse Flux Machine (SPM-TFM) calculated by Finite Element Analysis (FEA) and the analytical model.

The error in the functionality of the analytical model is mainly caused by neglecting the role of iron saturation and error in estimating the armature flux density, as represented in Figure 8.

The main component of the Back-EMF, which is calculated by Eq. (17), is compared with the FEA and presented in Figure 11. It can be seen that the maximum divergence between the analytical and the FEA results in the worst case is $10 \%$.

\section{3D Non-linear MEC}

Magnetic Equivalent Circuit (MEC) method is an analytical method for modeling electromagnetic machines $[31,32]$. The MEC has been successfully developed for different types of electrical machines in the literature [33-39]. In TFPMs, due to the 3-Dimensional (3D) nature of the flux path, 3D MEC is required. Compared with the FEA, the MEC is a faster method for reducing the computational time of the simulations. However, it is usually less accurate than the FEA. Hence, to increase the accuracy of the MEC, the iron saturation effect is modeled in this study.

\subsection{3-D permeance network}

The proposed permeance network for the SPM-TFM (proposed topology) is presented in Figure 12 from two viewpoints. To avoid the confusion, the variable air gap permeances are excluded from Figure 12. In order to model the rotor teeth permeances precisely, each rotor tooth and each rotor slot are modeled in three regions. The saturation effect is considered for the rotor tooth and stator iron permeances because of the high value of mangnetic flux density (the description is given in the next subsection). Due to the low magnetic flux density in the rotor yoke, the iron parts of the rotor yoke are modeled as constant permeances (no saturation effect). For instance, based on the parametric dimensions shown in Figure $13, G_{t 1}, G_{s 1}, G_{c 1}, G_{r 1}$ are calculated as in Eqs. (18)-(21), respectively:

$$
\begin{aligned}
G_{t 1} & =\frac{3 \mu_{t 1} L_{r} \tau}{Y_{s}} \\
G_{s 1} & =\frac{3 \mu_{0} L_{r}\left(3 \tau+W_{r s}\right)}{4 Y_{s}} \\
G_{c 1} & =\frac{p \mu_{c} L_{r} Y_{r}}{3 \pi\left(D_{o r}-2 Y_{s}-Y_{r} / 3\right)}, \\
G_{r 1} & =\frac{3 \pi \mu_{c} L_{r}\left(D_{o r}-2 Y_{s}-Y_{r} / 3\right)}{p Y_{r}}
\end{aligned}
$$

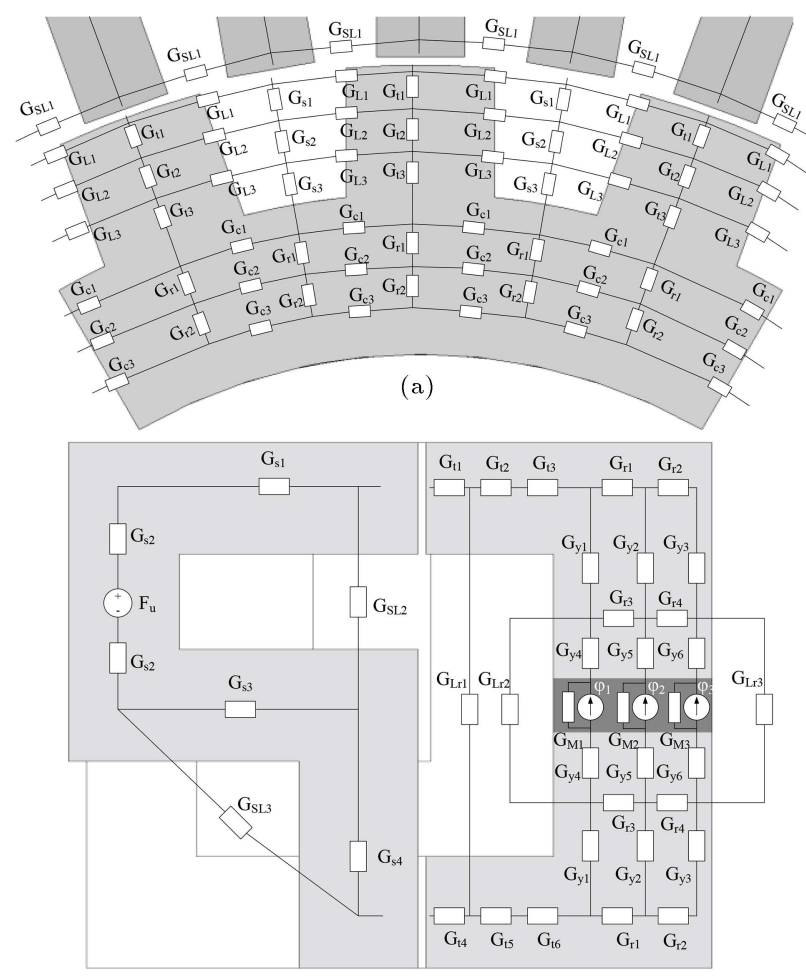

(b)

Figure 12. Cross sectional view of the proposed Single Permanent Magnet-Transverse Flux Machine (SPM-TFM) permeance network (excluding variable air gap permeances): (a) Front view and (b) side view. 


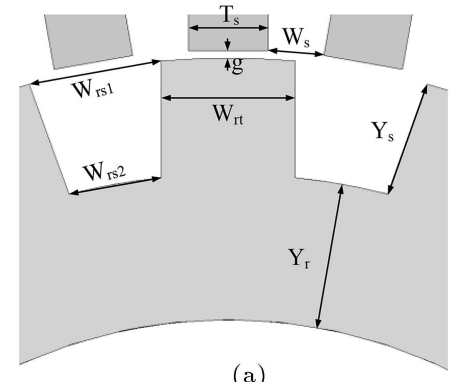

(a)

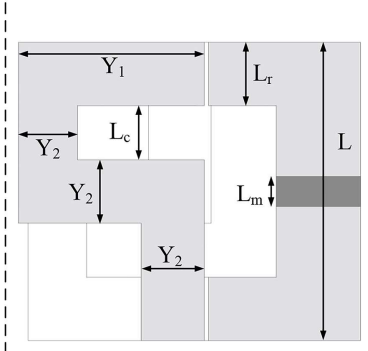

(b)

Figure 13. Parametric dimensions of the proposed Single Permanent Magnet-Transverse Flux Machine

(SPM-TFM): (a) Front view and (b) side view.

where $\mu_{t 1}$ is the permeability of the iron which is a variable depending on the working point in the iron B$\mathrm{H}$ curve; $\mu_{c}$ is the permeability of iron for the iron parts whose saturation effect is not modeled (rotor yoke); $\mu_{0}$ is the permeability of air; and $D_{\text {or }}$ and $D_{i r}$ are the outer and inner diameters of the rotor, respectively.

The rotor leakage permeances shown in Figure $13(\mathrm{~b})$ are calculated through Eqs. (22)-(24):

$$
\begin{aligned}
G_{L r 1} & =\frac{\mu_{0} Y_{s} \tau}{L-2 L_{r}}, \\
G_{L r 2} & =\frac{\mu_{0}\left(D_{o r}-Y_{s}\right)}{p} \times L n\left(\frac{L-2 L_{r}}{L_{m}}\right), \\
G_{L r 3} & =\frac{\mu_{0} D_{i r}}{p} \times \operatorname{Ln}\left(\frac{L}{L_{m}}\right) .
\end{aligned}
$$

Each segment of the ring-shaped PM is modeled by a current source shunted by a leakage permeance as in Eqs. (25) and (26):

$$
\begin{aligned}
& \varphi_{1}=\pi B_{r} \frac{\left(D_{o r}-2 Y_{s}\right)^{2}-\left(D_{o r}-2 Y_{s}-2 Y_{r} / 3\right)^{2}}{4 p}, \\
& G_{M 1}= \\
& \frac{\pi \mu_{P M}\left[\left(D_{o r}-2 Y_{s}\right)^{2}-\left(D_{o r}-2 Y_{s}-2 Y_{r} / 3\right)^{2}\right]}{4 p L_{m}},
\end{aligned}
$$

where $B_{r}$ and $\mu_{P M}$ are the PM remanent flux density and PM permeability, respectively.

The Magneto Motive Force (MMF) of each winding is modeled by a voltage source as follows:

$$
F_{u}=N_{u} I_{u}
$$

where $N_{u}$ is the upper coil's number of turns and $I_{u}$ is the armature current conducted by the upper coil.

\subsection{Variable air gap permeance}

In MEC modeling for electrical machines, the variable

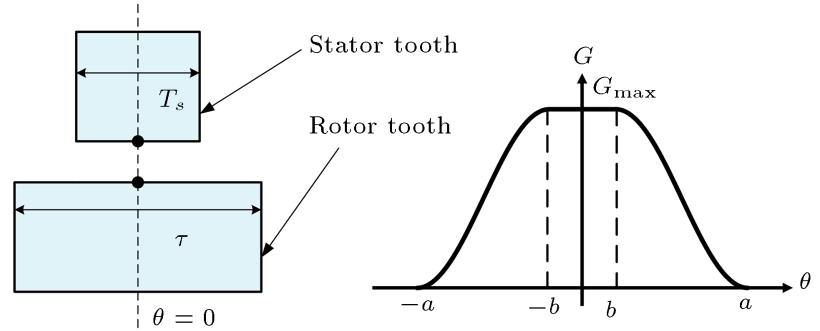

(a)

(b)

Figure 14. Model of the variable air gap permeances.

air gap permeances are the most important parts of the permeance network as energy conversion takes place in the air gap region. Therefore, the more precise the variable air gap permeance modeling, the more accurate the MEC results. The method of modeling air gap permeances is based on the proposed method of [31] in which the air gap permeance between one rotor tooth and one stator tooth during the rotation is considered, as given in Figure 14. The corresponding parameters of Figure 14 are given in Eqs. (28) and (29):

$$
\begin{aligned}
& G_{\max }=\frac{C_{f} \times \mu_{0} L_{r} \times \min \left(\tau, T_{s}\right)}{g}, \\
& a=\frac{2 \pi}{p}, \quad b=\frac{\left|\tau-T_{s}\right|}{D_{o r}} .
\end{aligned}
$$

Based on Figure 14, the permeance between two certain nodes of stator and rotor is equal to $G_{\max }$ when the angle between them $(\theta)$ is within $-b$ and $b$. In this condition, the maximum overlap between stator and rotor tooth occurs, leading to maximum permeance between the teeth. Moreover, the permeance follows a sinusoidal function when $|b|<|\theta|<|a|$. Beyond those limits, the permeance value is zero in Eq. (30) as follows:

$$
G= \begin{cases}G_{\max }, & b>\theta>-b \\ G_{\max } \frac{1+\cos \left(\pi \frac{\theta-b}{a-b}\right)}{2}, & a>\theta>b \\ G_{\max } \frac{1+\cos \left(\pi \frac{\theta+b}{a-b}\right)}{2}, & -b>\theta>-a \\ 0, & \text { elsewhere }\end{cases}
$$

\subsection{Iron saturation effect}

As mentioned earlier, to enhance the accuracy of the MEC method, modeling the iron saturation effect is required. This effect is considered for the rotor tooth permeance and stator permeance whose magnetic flux density is of high value. The non-linear MEC algorithm of the TFPM is presented in Figure 15. At the beginning, the machine physical parameters are inserted. Next, a function $\left(B=f_{(H)}\right)$ is fitted on 


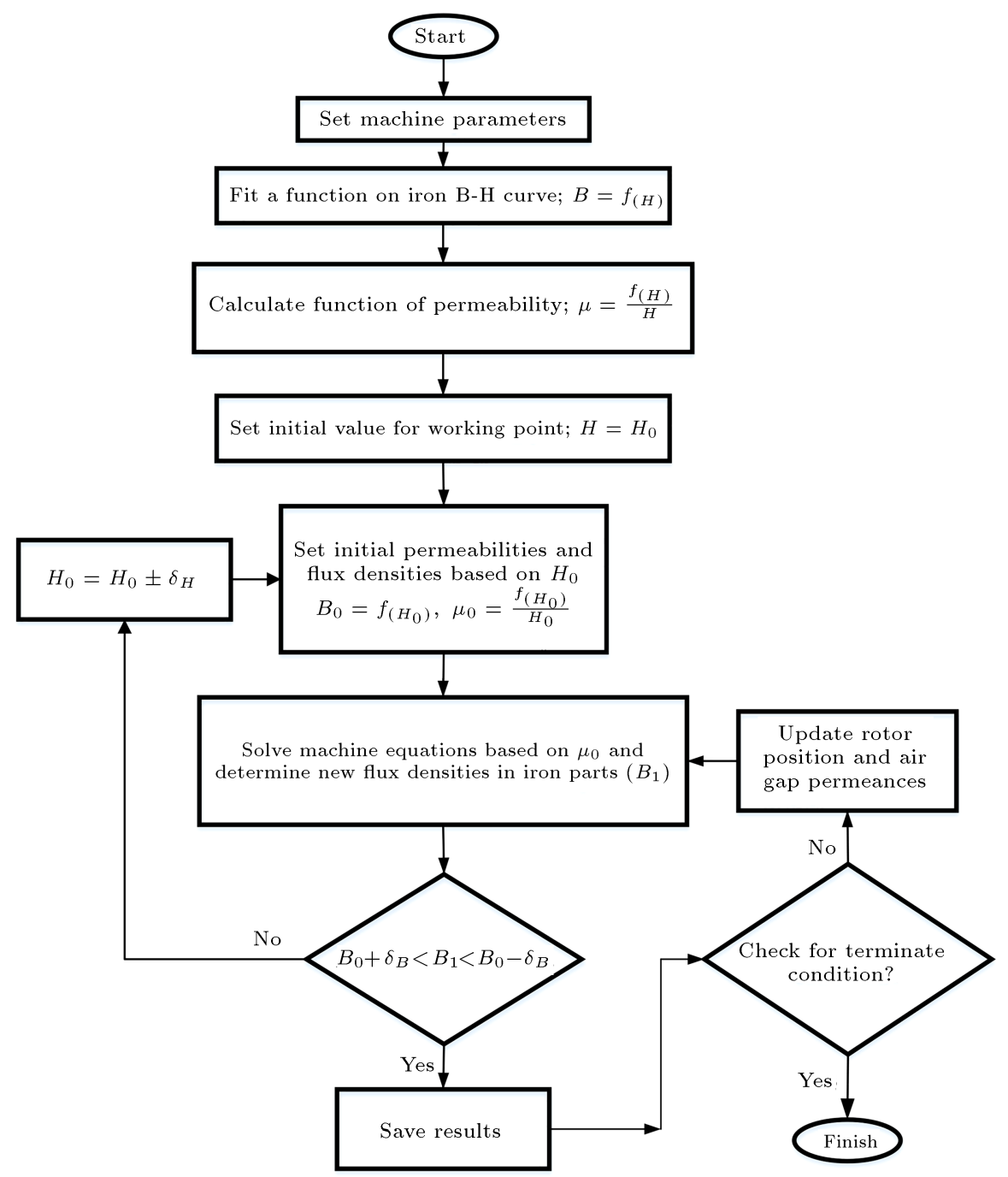

Figure 15. Non-linear Magnetic Equivalent Circuit (MEC) algorithm of the proposed Single Permanent Magnet-Transverse Flux Machine (SPM-TFM).

the iron B-H curve. Therefore, the function of iron permeability $\left(\mu=f_{(H)} / H\right)$ is calculated. Next, an initial working point for the iron part is assumed $\left(H_{0}\right.$, $\left.B_{0}, \mu_{0}\right)$. Afterwards, the MEC matrixes are solved and a new working point is determined for the iron part $\left(H_{1}, B_{1}, \mu_{1}\right)$. If the new flux density $\left(B_{1}\right)$ is close enough to the assumed value of flux density $\left(B_{0}\right)$, then the results of this step are saved and the rotor position is updated and the next step begins. Otherwise, the initial working point is wrong; instead, a new working point is assumed. This process is repeated until the initial and final values of flux density $\left(B_{0}\right.$ and $\left.B_{1}\right)$ get close enough. The parameter $\delta_{B}$ determines how much the two flux densities should get close. The parameter $\delta_{H}$ determines the change step of the iron working point. The smaller the above values $\left(\delta_{B}\right.$ and $\left.\delta_{H}\right)$, the more accurate the saturation modeling, yet at the cost of longer processing time. Consequently, these two values must be chosen wisely.

\section{4. $M E C$ results}

The total flux linkage of the TFPM in the no-load condition is extracted by both FEA and MEC methods and shown in Figure 16. Moreover, the net output voltage of the machine in the no-load condition is calculated by both methods and presented in Figure 17. As can be seen, the maximum flux linkage resulting from $\mathrm{MEC}$ is about $0.006 \mathrm{~Wb}$. Turn higher than the FEA result. Consequently, the MEC method is employed to calculate the peak of induced voltage to be about $10 \mathrm{~V}$ higher than the FEA (Figure 17). The three-phase cogging torque is also calculated by both methods and presented in Figure 18. Unlike the flux linkage and induced voltage, the MEC method is subject to noticeable errors $(12 \%)$ in cogging torque calculation.

According to no-load analysis, it is deduced that the MEC method has acceptable accuracy in calculating voltage and flux linkage, although it may not 


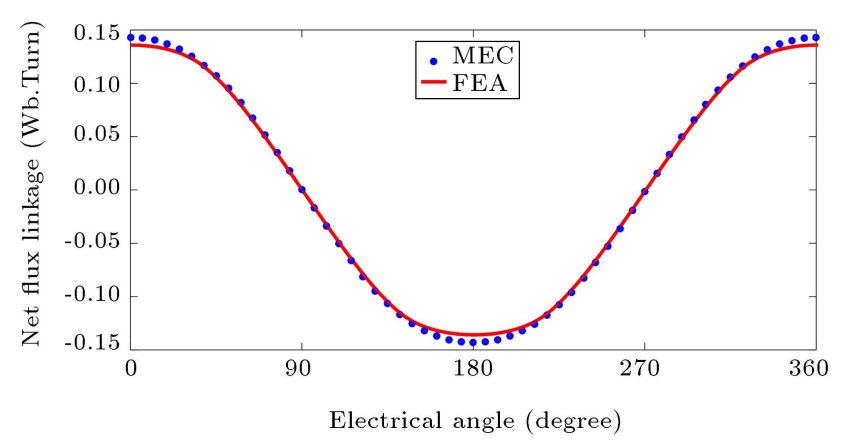

Figure 16. Comparison of the net flux linkage in Magnetic Equivalent Circuit (MEC) method and the Finite Element Analysis (FEA) (no-load condition).

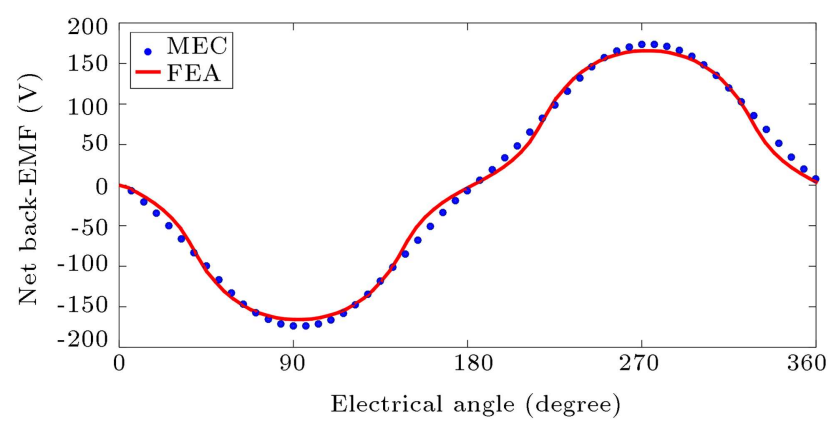

Figure 17. Comparison of the net Back-EMF of the proposed Single Permanent Magnet-Transverse Flux Machine (SPM-TFM) in Magnetic Equivalent Circuit (MEC) method and the Finite Element Analysis (FEA).

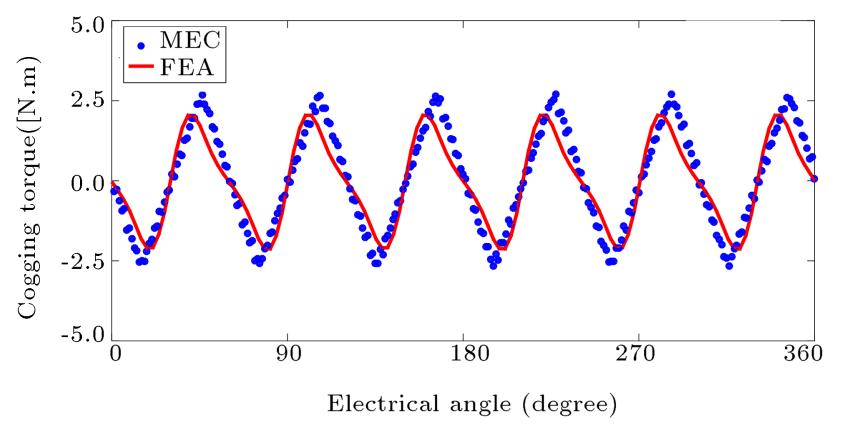

Figure 18. Cogging torque of the proposed Single Permanent Magnet-Transverse Flux Machine (SPM-TFM) resulting from Magnetic Equivalent Circuit (MEC) method and the Finite Element Analysis (FEA).

be accurate in calculating the cogging torque. In the case of full load analysis in the generator mode, the load voltage is calculated using both methods, as presented in Figure 19. The comparison shows that the MEC method has an acceptable level of adoption with the FEA in the full-load condition. In terms of the processing time, the MEC method is 20 times faster than the FEA method. The MEC method is significantly faster than the FEA which would save a noticeable amount of time, especially for optimization purposes.

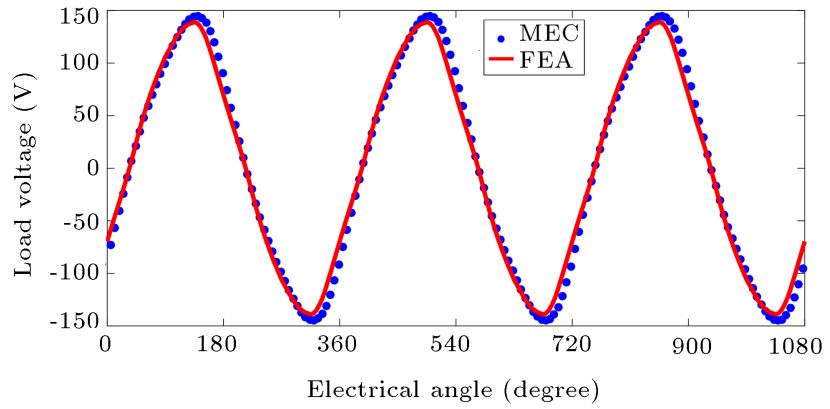

Figure 19. Comparison of full load voltages of the proposed Single Permanent Magnet-Transverse Flux Machine (SPM-TFM) resulting from Magnetic Equivalent Circuit (MEC) method and the Finite Element Analysis (FEA).

\section{Results and comparisons}

To achieve a better insight into the magnetic characteristic of the topologies, simulations have been conducted based on FEA. The magnetic flux density distribution in one pole pair of the basic topology is depicted in Figure 20(a). As can be seen, when the rotor teeth are aligned with the U-shaped cores, the I-shaped cores are aligned with the rotor slots. Thus, the main portion of the flux passes through the U-shaped core and results in maximum flux linkage. Figure 20(b) represents the magnetic flux density distribution in the proposed topology. Similarly, in the basic position, most of the PM fluxes are linked to the upper coil, while the lower coil has minimum flux linkage.

According to Figure 9 and Eq. (15), the leakage magnetic flux density $\left(B_{\min }^{\prime}\right)$ under the rotor slot will cause a reduction in the machine rating. The leakage flux can be reduced by increasing the spacing between stator parts which would result in increasing the machine diameter. Therefore, a compromise must be made between minimizing $B_{\min }^{\prime}$ and the machine diameter.

In order to compare the SPM-TFMs performance, the output voltage in both no-load and full-load conditions is extruded. Moreover, demagnetization characteristics of the machines are analyzed.

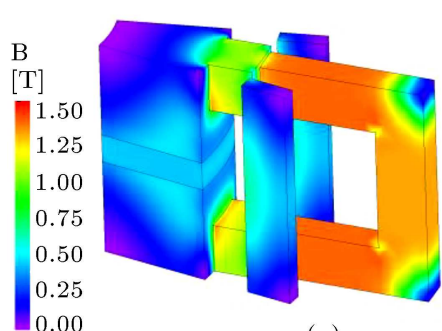

(a)

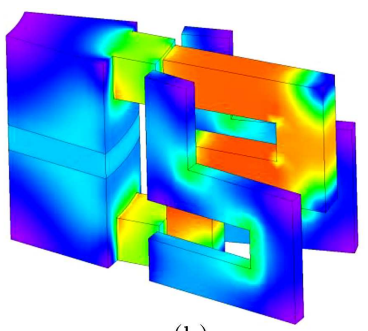

(b)
Figure 20. Flux density distribution in one pole pair of Single Permanent Magnet-Transverse Flux Machines (SPM-TFMs): (a) Basic topology and (b) proposed topology. 


\subsection{Voltage harmonics component}

\subsubsection{No-load performance}

The Back-EMF waveform and its harmonic component spectrum analysis are presented in Figure 21. As can be seen, the odd-order components of Back-EMF for both topologies are almost equal. On the contrary, the even-order harmonics are all cancelled in the case of the proposed topology while having a significant value in the basic topology.

\subsubsection{Full-load performance}

Figure 22(a) presents the phase voltage of both topologies under equal load. It can be found that the basic topology suffers even-order harmonics that cause an unbalanced behavior at the positive and negative peaks of its voltage waveform. In contrast, for the proposed topology, the voltage is completely balanced. This fact can be easily seen in the harmonics component spectrum of the voltages in Figure 22(b). As is clear in this figure, the main component of the voltage in the proposed topology is slightly higher in value than that in the basic topology. More importantly, the second harmonic has a significant value in the case of basic topology, while it is cancelled in the proposed topology.

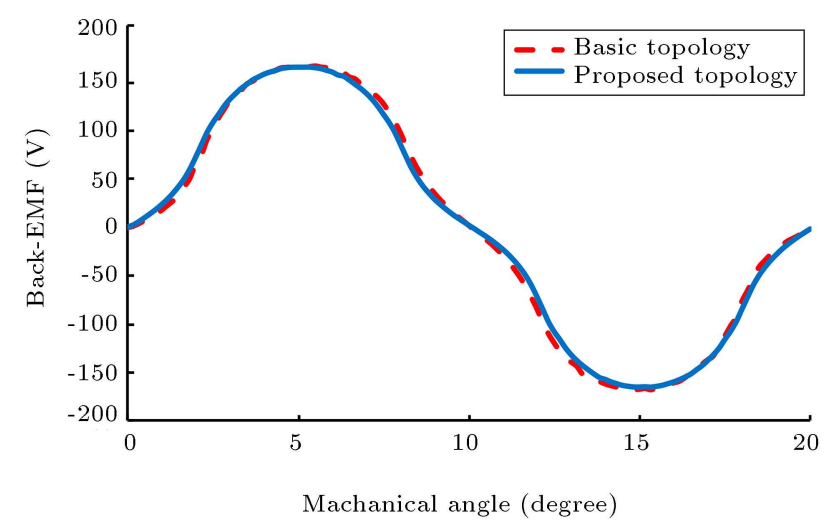

(a)

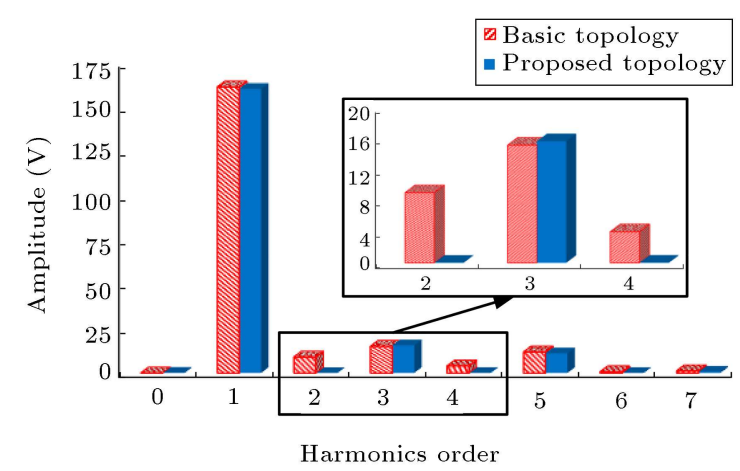

(b)

Figure 21. Output voltage of the Single Permanent Magnet-Transverse Flux Machines (SPM-TFMs) in the no load condition: (a) Waveform and (b) harmonics component.

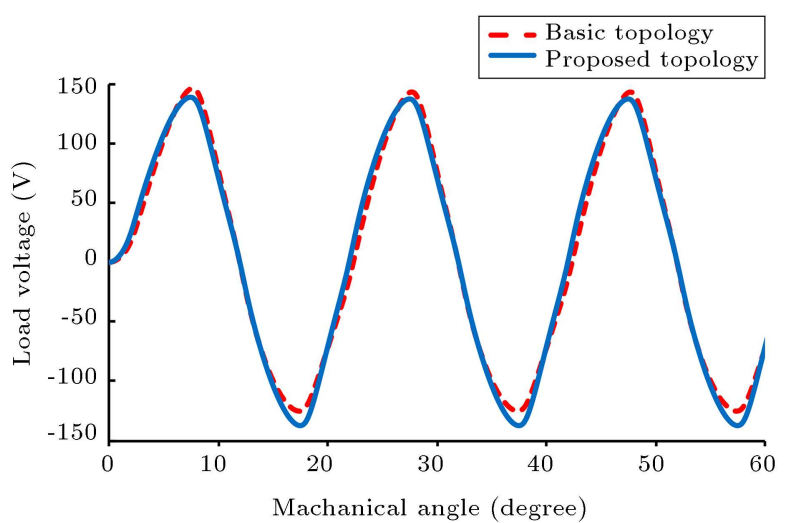

(a)

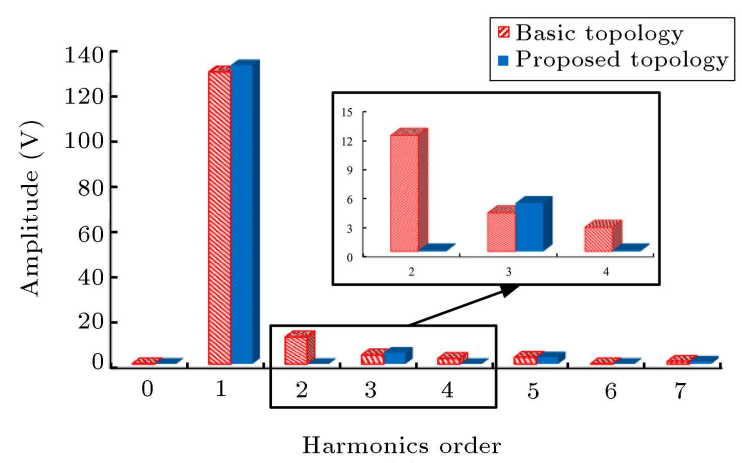

(b)

Figure 22. Output voltage of the Single Permanent Magnet-Transverse Flux Machines (SPM-TFMs) in the full load condition: (a) Waveform and (b) harmonics component.

\subsection{Demagnetisation behaviour}

Demagnetization phenomenon of PMs, especially in low energy magnets like ferrite PMs, is one of the main concerns of designers. This effect mainly occurs in high armature currents due to short circuit fault, inverter fault, etc. High value of armature current (either continues or instantaneous) may cause irreversible demagnetization to $\mathrm{PMs}$ which affects the machine performance permanently. In this section, it is shown that the basic topology is highly vulnerable to the high armature currents as the PM is easily demagnetized. Contrarily, it is depicted that the proposed topology is significantly resistant.

To compare the PM demagnetization in both topologies, various currents in $d$-axis (the position presented in Figure 25) are injected to the machines and the mean value of the magnetic flux densities per magnet volume is calculated. Figure 23 presents the mean value of PM magnetic flux densities in the axial direction (magnetization direction) for both topologies in various currents. As can be seen, flux density in the basic topology declines dramatically upon increasing the armature current and at $150 \mathrm{~A}$, it turns to negative values. Through further increase in the armature current, the average flux density drops 


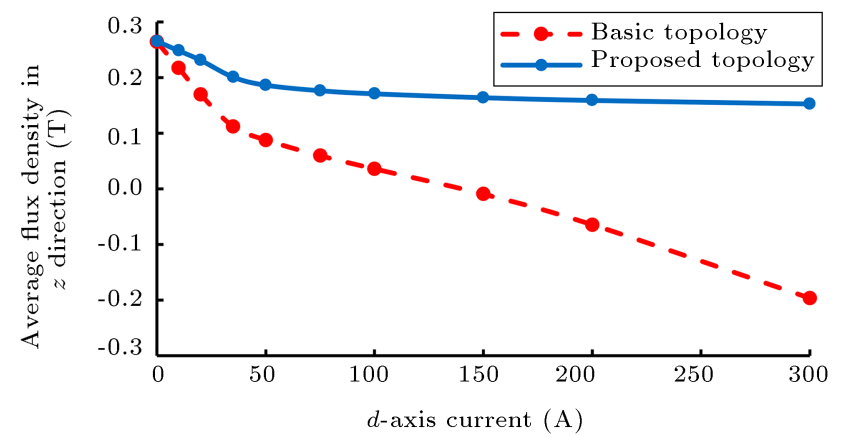

Figure 23. Average flux density of Permanent Magnet (PM) (in the magnetization direction $(Z)$ ) at different $d$-axis currents for basic topology and proposed topology.

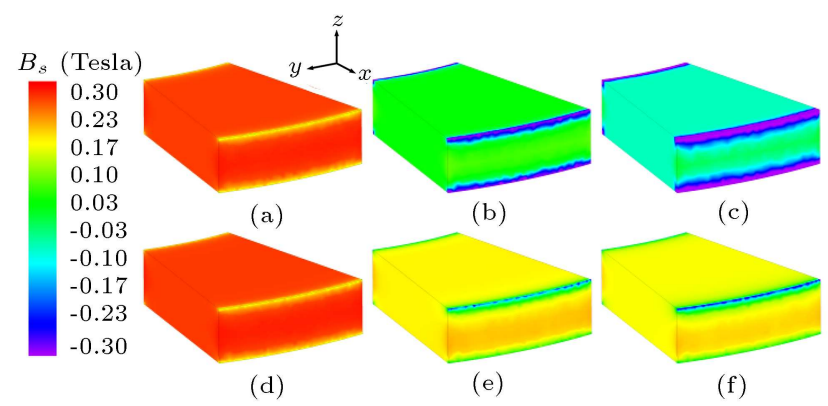

Figure 24. Magnetic flux density of the Permanent Magnet (PM) (in magnetisation direction $(Z)$ ) for both topologies under different $d$-axis currents. Basic topology: (a) 0 Ampere, (b) 100 Ampere, and (c) 200 Ampere. Proposed topology: (d) 0 Ampere, (e) 100 Ampere, and (f) 200 Ampere.

to -0.1 Tesla where the irreversible demagnetization of the Ferrite PM happens. However, as can be seen in Figure 23, the proposed machine is extremely rigid against the demagnetization effect such that it has not experienced this effect even by 300 A current injection. To have a better understanding of the rigidity of the proposed machine against the demagnetization effect, the magnetic flux density distribution in $1 / 18$ of the structure by applying 0, 100, and 200 Amperes of current is extracted and presented in Figure 24. The magnetic behavior of both structures is the same in the no-load condition (Figure 24(a) and (d)). By injecting 100 A current, a considerable difference in flux distribution content appears where the value of the magnetic flux density in the basic and proposed topologies reaches 0.05 and 0.17 Tesla, respectively (Figure 24(b) and (e)). At the injected current of $200 \mathrm{~A}$, the magnetic flux density of PM in the basic topology declines to 0.1 Tesla, while the flux density for the proposed topology does not change significantly (Figure 24(c) and (f)). To explain the reason behind this significant difference in the demagnetization behavior of the topologies, a vector plot of the magnetic flux density distribution at 200 A current is extracted and shown in Figure 25. In the basic topology, it is

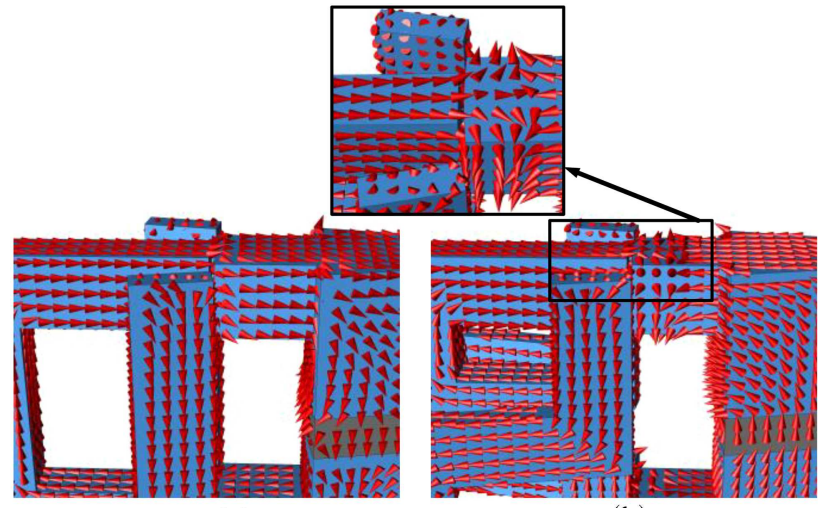

(a)

(b)

Figure 25. Vector plot of the magnetic flux density distribution in the topologies at 200 A current ( $d$-axis): (a) Basic topology and (b) proposed topology.

shown that the flux in the U-shaped core, resulting from armature current, passes through the rotor teeth and mainly closes its path by crossing the PM, which causes PM demagnetization. In the proposed topology, the resulting flux of the upper coil and the PM passes through the rotor teeth and is conducted to the side stator iron parts that surround the lower coil. Since the MMF of the upper and lower coils is characterized by opposite polarities, the sides of the stator tend to conduct the flux via itself. This is the main reason for the above-mentioned phenomenon and the lower rate of demagnetization in the proposed topology.

\section{Optimization of torque profile of the proposed machine}

In the case of the above-mentioned comparisons between the basic and proposed topologies, it can be easily deduced that the proposed machine has better operation characteristics in terms of PM demagnetisation and the harmonic component of the output voltage (elimination of all the even order harmonics). The electromagnetic torque of both TFPMs at different loadings is presented in Figure 26. As can be seen, the electromagnetic torque profile for both TFPMs has

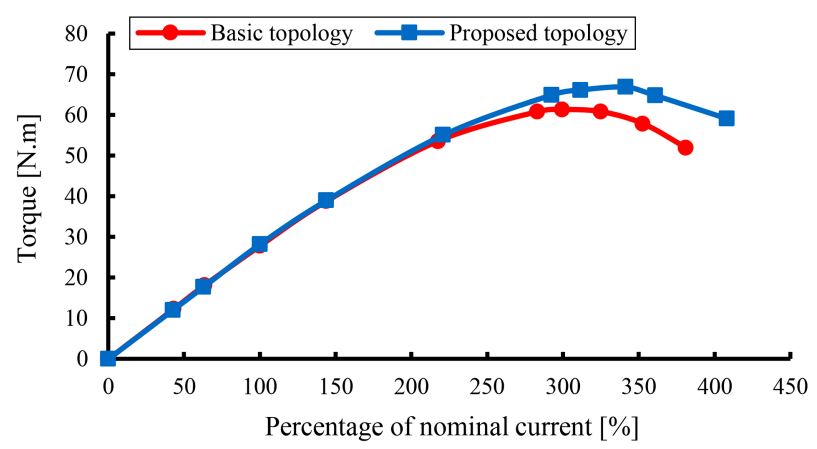

Figure 26. Electromagnetic torque of the Transvers Flux Permanent Magnets (TFPMs) in different currents (percentage of the nominal current). 
almost the same behavior until $150 \%$ of the nominal current. At higher currents, the proposed topology shows better performance. The difference is mainly due to three reasons:

- First, the armature flux density distribution in the air gap for the proposed topology is symmetric, while in the case of the basic topology, it is not symmetric (Figure 8);

- Second, the stator leakage permeances are different in two topologies;

- Third, the current waveform of the basic topology contains even order harmonics. In other words, at the equal rms current, the fundamental component of the current waveform is higher than that of the basic one, which results in higher torque production.

According to three main advantages of the proposed topology (cancelling all even order harmonics, better PM demagnetization behavior, and better torque production), the proposed topology can be the recommended candidate for a small-scale direct drive wind turbine. Since the electromagnetic torque of the generator plays an important role in the start-up and vibration level of a wind turbine, reducing the torque ripple of the structure is desired. To analyze the torque profile of the proposed machine, the profile of the cogging torque versus the rotor position is extracted and presented in Figure 27. As can be seen, both of topologies have a noticeable cogging torque (18\%) which will affect the generator output characteristic.

In order to minimize the torque ripple of the structure and ensure an optimized design, a method based on skewing the rotor teeth is developed. The skew of the rotor poles in typical topologies $[17,18]$ requires special shaping of the $\mathrm{PMs}$ which is not a costeffective solution. In case of the SPM-TFM topology, the rotor pole skew could be applied by skewing only the rotor teeth. Consequently, any special changing

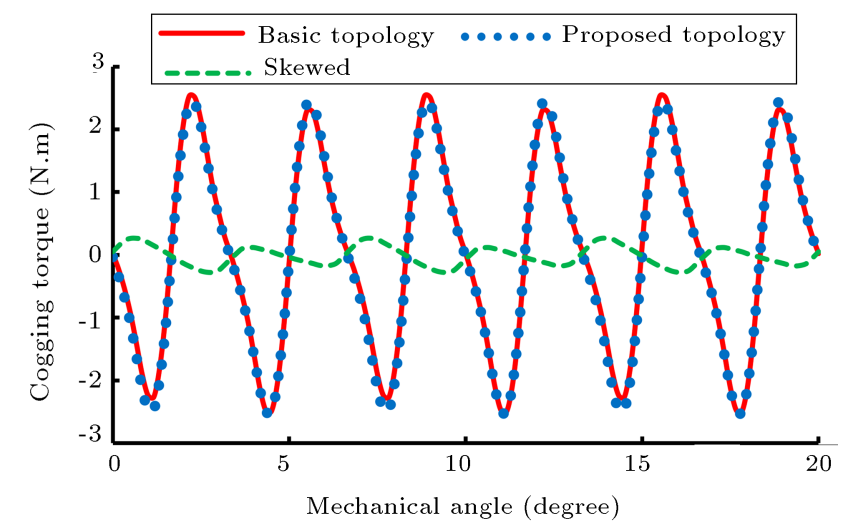

Figure 27. Cogging torque comparison for Single Permanent Magnet-Transverse Flux Machine (SPM-TFM) topologies. in PM shape is not necessary, anymore. Moreover, skewing the rotor teeth is a simple and cost-effective procedure in comparison with skewing the PMs.

To do so, the rotor teeth in the proposed machine are skewed at different angles and the profile of the electromagnetic torque is extracted and shown in Figure 28. As can be seen, changing the skew angle has a considerable effect on the value of average torque and torque ripple. Since the result of changing skew angle does not have a linear effect on machine torque characteristic, a sensitivity analysis of the skew angle on the average torque and torque ripple is conducted and the result is presented in Figure 29. Regarding the mechanical constraints in the machine design, skewing at 7 degrees will be operational. By increasing the skew angle from zero to 7 degrees, the average torque keeps dropping almost linearly and achieves a $14.4 \%$ drop in the final degree. Effect of increasing the skew angle on the torque ripple is not linear. As can be seen from Figure 29, torque ripple goes through an oscillation from 4 to 7 degrees. It is a fact that the minimum torque ripple belongs to 7 degrees of the

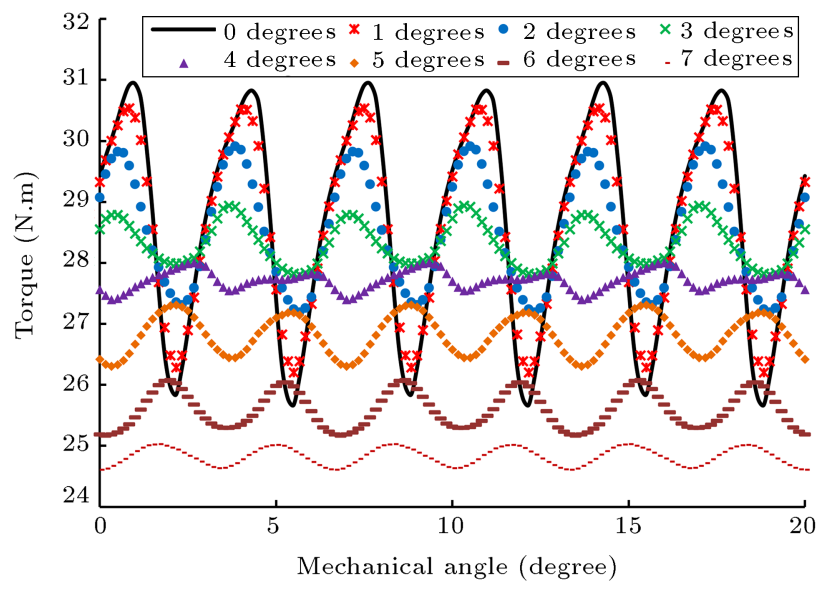

Figure 28. Torque waveform of the Single Permanent Magnet-Transverse Flux Machine (SPM-TFM) in different skew angles.

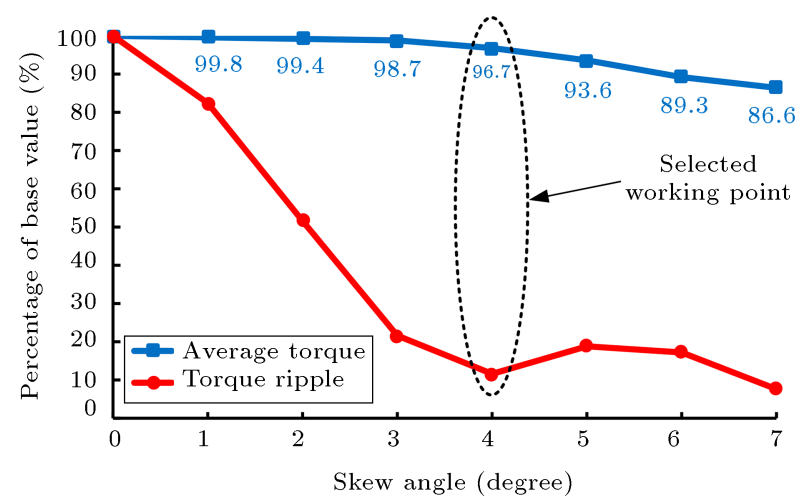

Figure 29. Torque characteristics of the Single Permanent Magnet-Transverse Flux Machine (SPM-TFM) in different skew angles. 


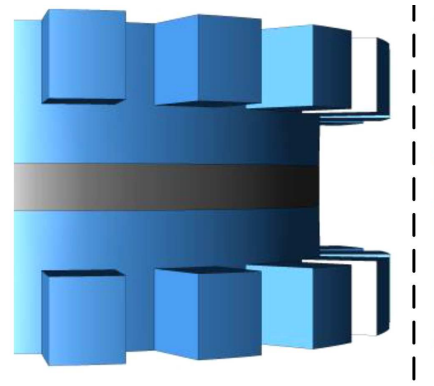

(a)

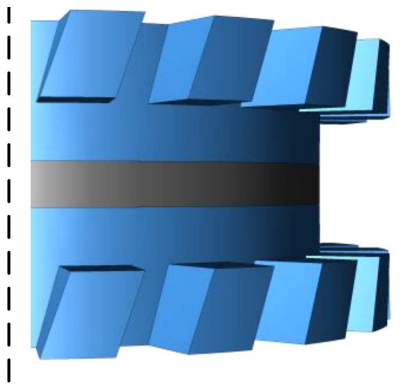

(b)
Figure 30. Final rotor configuration before and after 4-degree skewing: (a) Before skew and (b) after 4-degree skewing.

skew in the rotor teeth, but the average torque drops considerably at this point. By allowing a maximum $10 \%$ drop in average toque, the minimum torque ripple could be achieved by skewing the rotor teeth at 4 degrees. Therefore, the torque ripple is reduced to $12 \%$ by only a $3.3 \%$ drop in the average torque. The cogging torque of the SPM-TFMs before and after 4degree skewing is depicted in Figure 27. The cogging torque is reduced almost $90 \%$ after 4 -degree skewing of rotor teeth. The final rotor configuration after and before 4-degree skewing is presented in Figure 30.

\section{Conclusion}

In this study, a transverse flux Permanent Magnet (PM) generator was proposed that enjoyed the advantages of using cheap Ferrite PM with a bipolar flux linkage. Unlike the basic topology, having the bipolar flux linkage of the proposed machine led to cancelling all the even order harmonics in the output voltage profile. The output equations are extracted to model the machine and develop the design algorithm. The analytical approach along with numerical analysis reveals that the demagnetization risk of the Ferrite was reduced significantly by splitting the armature reaction into two armature coils. To optimize the design for a wind turbine application, rotor teeth skewing was employed and the cogging torque and torque ripple were reduced by almost $90 \%$, thus maintaining the average torque above $96 \%$.

\section{References}

1. Gieras, J.F. "Permanent magnet motor technology: design and applications", pp. 364-401, CRC press, Florida, USA (2009).

2. Pourmoosa, A.A. and Mirsalim, M. "A transverse flux generator with a single row of permanent magnets: Analytical design and performance evaluation", IEEE Transactions on Industrial Electronics, 66(1), pp. 152161 (2018).

3. Dobzhanskyi, O., Gouws, R., and Amiri, E. "Analysis of PM transverse-flux outer rotor machines with dif- ferent configuration", IEEE Transactions on Industry Applications, 53(5), pp. 4260-4268 (2017).

4. Husain, T., Hasan, I., Sozer, Y., Husain, I., and Muljadi, E. "Design considerations of a transverse flux machine for direct-drive wind turbine applications", IEEE Transactions on Industry Applications, 54(4), pp. 3604-3615 (2018).

5. McDonald, A. and Bhuiyan, N.A. "On the optimization of generators for offshore direct drive wind turbines", IEEE Transactions on Energy Conversion, 32(1), pp. 348-358 (2016).

6. Jia, Z., Lin, H., Fang, S., and Huang, Y. "Cogging torque optimization of novel transverse flux permanent magnet generator with double C-hoop stator", IEEE Transactions on Magnetics, 51(11), pp. 1-4 (2015).

7. Husain, T., Hasan, I., Sozer, Y., Husain, I., and Muljadi, E. "Cogging torque minimization in transverse flux machines", IEEE Transactions on Industry Applications, 55(1), pp. 385-397 (2018).

8. Arand, S.J. and Ardebili, M. "Cogging torque reduction in axial-flux permanent magnet wind generators with yokeless and segmented armature by radially segmented and peripherally shifted magnet pieces", Renewable Energy, 99, pp. 95-106 (2016).

9. Vaz, J.R., Wood, D.H., Bhattacharjee, D., and Lins, E.F. "Drivetrain resistance and starting performance of a small wind turbine", Renewable Energy, 117, pp. 509-519 (2018).

10. Oh, J.H. and Kwon, B.I. "Design, optimization, and prototyping of a transverse flux-type-switched reluctance generator with an integrated rotor", IEEE Transactions on Energy Conversion, 31(4), pp. 15211529 (2016).

11. Ahsanullah, K., Dutta, R., and Rahman, M.F. "Analysis of low-speed IPMMs with distributed and fractional slot concentrated windings for wind energy applications", IEEE Transactions on Magnetics, 53(11), pp. 1-10 (2017).

12. Ueda, Y. and Takahashi, H. "Transverse-flux motor design with skewed and unequally distributed armature cores for reducing cogging torque", IEEE Transactions on Magnetics, 53(11), pp. 1-5 (2017).

13. Liu, C., Zhu, J., Wang, Y., Lei, G., and Guo, Y. "Cogging torque minimization of SMC PM transverse flux machines using shifted and unequal-width stator teeth", IEEE Transactions on Applied Superconductivity, 26(4), pp. 1-4 (2016).

14. Wang, Q., Zhao, B., Zhao, H., Li, Y., and Zou, J. "Optimal design of tubular transverse flux motors with low cogging forces for direct drive applications", IEEE Transactions on Applied Superconductivity, 26(7), pp. $1-5$ (2016).

15. Washington, J.G., Atkinson, G.J., and Baker, N.J. "Reduction of cogging torque and EMF harmonics in modulated pole machines", IEEE Transactions on Energy Conversion, 31(2), pp. 759-768 (2016). 
16. Nasiri-Zarandi, R., Ghaheri, A., and Abbaszadeh, K. "Cogging torque reduction in U-core TFPM generator using different halbach-array structures", In 2018 International Symposium on Power Electronics, Electrical Drives, Automation and Motion (SPEEDAM), Amalfi Coast, Italy, pp. 1153-1158 (2018).

17. Green, J. "Development of high-performance generator for wind turbines", Final Report, Stage II, National Wind Technology Center, Boulder, USA (2009).

18. Gieras, J.F., Hamilton Sundstrand Corp. "Transverse flux machine", U.S. Patent 7,830,057 (2010).

19. Kastinger, G. "August. Design of a novel transverse flux machine", In Proc. ICEM, Brugge, Belgium (2002).

20. Liu, C., Lei, G., Ma, B., Wang, Y., Guo, Y., and Zhu, J. "Development of a new low-cost 3-D flux transverse flux FSPMM with soft magnetic composite cores and ferrite magnets", IEEE Transactions on Magnetics, 53(11), pp. 1-5 (2017).

21. Husain, T., Hasan, I., Sozer, Y., Husain, I., and Muljadi, E. "Design of a modular E-core flux concentrating transverse flux machine", IEEE Transactions on Industry Applications, 54(3), pp. 2115-2128 (2018).

22. Bastawade, P., Chaudhari, B.N., Ugale, R.T., and Pramanik, A. "Analytical and FEA based analysis of homopolar poly-phase transverse flux machine", In 2016 IEEE International Conference on Power Electronics, Drives and Energy Systems (PEDES), Trivandrum, India, pp. 1-6 (2016).

23. Liu, G., Shao, M., Zhao, W., Chen, Q., and Mo, L. "Cost reduction of a new fault-tolerant Halbach permanent magnet machine using ferrite magnet", IEEE Transactions on Magnetics, 50(11), pp. 1-4 (2014).

24. Zhao, X. and Niu, S. "Design of a novel consequentpole transverse-flux machine with improved permanent magnet utilization", IEEE Transactions on Magnetics, 53(11), pp. 1-5 (2017).

25. Ahmed, A., Wan, Z., and Husain, I. "Permanent magnet transverse flux machine with overlapping stator poles", In 2015 IEEE Energy Conversion Congress and Exposition (ECCE), Montreal, Canada, pp. 791-798 (2015).

26. Óskarsdóttir, M.Ó. "A general description and comparison of horizontal axis wind turbines and vertical axis wind turbines", Doctoral Dissertation, School of Engineering and Natural Sciences, University of Iceland, Iceland, pp. 130-365 (2014).

27. Nasiri-Zarandi, R., Ajamloo, A.M., and Abbaszadeh, K. "Proposing the output equations and 3-D MEC modeling for U-Core TFPM generators", In 2018 International Symposium on Power Electronics, Electrical Drives, Automation and Motion (SPEEDAM), Amalfi Coast, Italy, pp. 292-297 (2018).
28. Anglada, J.R. and Sharkh, S.M. "Analytical calculation of the torque produced by transverse flux machines", IET Electric Power Applications, 11(7), pp. 1298-1305 (2017).

29. Anglada, J.R. and Sharkh, S.M. "Analysis of transverse flux machines using a virtual mutual inductance approach", IEEE Transactions on Energy Conversion, 33(2), pp. 465-472 (2017).

30. Alam, F.R. and Abbaszadeh, K. "Magnetic field analysis in eccentric surface-mounted permanentmagnet motors using an improved conformal mapping method", IEEE Transactions on Energy Conversion, 31(1), pp. 333-344 (2015).

31. Ostovic, V., Dynamics of Saturated Electric Machines, pp. 112-368, Springer Science \& Business Media, Berlin, Germany (2012).

32. Sudhoff, S.D., Power Magnetic Devices: A MultiObjective Design Approach, John Wiley \& Sons, New Jersey, USA, pp. 264-355 (2014).

33. Ojaghlu, P., Vahedi, A., and Totoonchian, F. "Magnetic equivalent circuit modelling of ring winding axial flux machine", IET Electric Power Applications, 12(3), pp. 293-300 (2017).

34. Tong, W., Wang, S., Dai, S., Wu, S., and Tang, R. "A quasi-three-dimensional magnetic equivalent circuit model of a double-sided axial flux permanent magnet machine considering local saturation", IEEE Transactions on Energy Conversion, 33(4), pp. 21632173 (2018).

35. Horvath, D.C., Pekarek, S.D., and Sudhoff, S.D. "A scaled mesh/nodal formulation of magnetic equivalent circuits with motion", IEEE Transactions on Energy Conversion, 34(1), pp. 58-69 (2018).

36. Mignot, R.B., Espanet, C., Chamagne, D., and Martin, T. "Modeling of an axial flux pm motor using a 3D magnetic equivalent circuit", In 2014 IEEE Vehicle Power and Propulsion Conference (VPPC), Coimbra, Portugal, pp. 1-9 (2014).

37. Johnson, M., Gardner, M.C., and Toliyat, H.A. "A parameterized linear magnetic equivalent circuit for analysis and design of radial flux magnetic gears-Part I: Implementation", IEEE Transactions on Energy Conversion, 33(2), pp. 784-791 (2017).

38. Hasan, I., Husain, T., Sozer, Y., Husain, I., and Muljadi, E. "Analytical modeling of a double-sided flux concentrating E-core transverse flux machine with pole windings", In 2017 IEEE International Electric Machines and Drives Conference (IEMDC), Miami, USA, pp. 1-7 (2017).

39. Hasan, I., Husain, T., Uddin, M.W., Sozer, Y., Husain, I., and Muljadi, E. "Analytical modeling of a novel transverse flux machine for direct drive wind turbine applications", In 2015 IEEE Energy Conversion Congress and Exposition (ECCE), Montreal, Canada, pp. 2161-2168 (2015). 


\section{Biographies}

Akbar Mohammadi Ajamloo was born in Chalus, Mazandaran, Iran in 1994. He received the BS degree in Electrical Engineering from K. N. Toosi University of Technology, Tehran, Iran in 2016. He achieved straight entrance into MS program in Electrical Engineering at K. N. Toosi University of technology and received the degree in 2018. He is currently an electrical machine designer with Damavand Electronics Corporation, Tehran, Iran. His research interests are permanent magnet wind generators, industrial electric motors, and variable speed drives.

Karim Abbaszadeh received BS degree in Communication Engineering from K. N. Toosi University of Technology, Tehran, Iran in 1991 and later, achieved his MS and PhD degrees in Electrical Engineering from Amir Kabir University of Technology, Tehran, Iran in 1997 and 2000, respectively. From 2001 to 2003, he was a Research Assistant at the Department of
Electrical Engineering, Texas A\&M University, College Station, TX, USA. He is currently a Professor at the Department of Electrical Engineering, K.N. Toosi University of Technology. His research interests include power electronic and dc-dc and dc-ac converters, electric machinery, variable-speed drives, and propulsion applications.

Reza Nasiri-Zarandi received the BS degree in Electrical Engineering from K. N. Toosi University of Technology, Tehran, Iran in 2008 and the MS degree in the same major jointly with Amir Kabir University of Technology, Tehran, Iran in 2010. He received the $\mathrm{PhD}$ degree in Electrical Engineering and Energy jointly with Amir Kabir University of Technology, Tehran, Iran, and the Polytechnic University of Turin, Turin, Italy. He is currently an Assistant Professor in the electrical machine group, Niroo Research Institute (NRI), Tehran, Iran. His research interests include design, modelling, FEA, optimization, and drive of rotary electric machines and power electronics. 